\title{
EL CRISTO DE LA LUZ DE TOLEDO. DOS SUPUESTAS MEZQUITAS EN UNA
}

Basilio PAVÓn MaLdonAdo.

CSIC

En el milenio de la terminación de la mezquita del Cristo de la Luz (999-1999)

Se viene aceptando en Toledo la existencia de varias mezquitas: Mezquita Mayor en donde se levanta la catedral, la del Cristo de la Luz, San Salvador o El Salvador, la de la Puerta de al-Dabbāgīn — no lejos del templo de San Sebastián - junto con la de Montefrío atribuida a un piadoso musulmán fallecido en 1013, San Lorenzo, la de las Tornerías, una junto a los baños del Caballel, Santas Justa y Rufina y, según Ibn Baškuwāl, la mezquita de Ibn Dunay el qāḍ̄ en el al-Hizām -Alficén - o gran recinto amurallado presidido por la alcazaba oficial. Había otros modestos oratorios o espacios sagrados en la amplia zona de la catedral y por el Pozo Amargo, que fueron vendidas por mitades a lo largo de la Edad Media. Y es más que probable la existencia de otros suplantados por templos mudéjares, entre ellos San Román, Santiago del Arrabal, San Bartolomé, San Andrés, San Miguel y San Sebastián, de probable identificación con la mezquita Dabbāgīn. Las fuentes escritas árabes poco o casi nada dicen de mezquitas y palacios de la ciudad.

El estudio que sigue tiene como finalidad básica poner en discusión la mezquita del Cristo de la Luz, erigida en jornada constructiva única del año 999, según reza la inscripción de su fachada de la calle, y hacer, de paso, una revisión de la arquitectura religiosa medieval toledana dado el cúmulo de incitaciones que atesora el Cristo de la Luz. Se podría admitir en éste un oratorio anterior a 999, de igual estructura y parecida fábrica, aunque más modesto que el actual. En síntesis, se trata de saber si toda la decoración superior de las fachadas noroeste y oeste —o de la calle-, incluidos los pseudo-contrafuertes de los ángulos y pilares de esas dos fachadas exteriores que sirven a aquélla de soporte, así como las cúpulas del interior, son revestimiento del año 999 añadido a modesto oratorio anterior allí mismo ubicado con planta de nueve tramos y cubrición menos sofisticada que la de ahora.

\section{INSCRIPCIÓN ÁRABE DE LA FACHADA DE LA CALLE}

La teoría de los dos templos en uno del Cristo de la Luz comienza con estudios sobre el monumento de Rodrigo Amador de los Ríos que en su lectura del 
epígrafe fundacional introdujo el término taŷdid, con la traducción de «renovar» o «reconstrucción»; con posterioridad, el epigrafista Ocaña Jiménez vio en ese grafema un nombre propio, Ibn Hadidi, personaje que ordena erigir el oratorio terminado en 999. Ocaña Jiménez traduce que «Aḥmad Ibn Hadīdī hizo erigir esta mezquita... y se terminó bajo la dirección de Mūsa Ibn 'Alī, el arquitecto, concluyéndose en 999». La expresión «se erigió» es traducción del vocablo aqāma que en epigrafías fundacionales de otras obras árabes toledanas y de fuera de Toledo es sutituido por bunyān o bi-bunyān, también banā; sin bien estos últimos términos a juicio de autoridades arabistas implican las acepciones «ordenó construir»y «ordenó restaurar». Ése, por ejemplo, es el caso de la inscripción de la debatida puerta de San Esteban de la Mezquita Mayor de Córdoba, rehecha o restaurada por el emir Muhammad I en el siglo IX, en la que se lee bun$y \bar{a} n$ o restauración, puesto que arqueológicamente está probado que gran parte de esa puerta data de "Abd al-Raḥmān I, en el siglo viII. También merece una alusión la mezquita mayor de Sfax, en Túnez, erigida en el siglo IX; una de las reformas acaecida en 988 consta en inscripción donde es empleado el verbo bană, sobre el que L. Golvin dice que en el dominio de la epigrafía tiene los sentidos de «construir», «agrandar», «restaurar». Trae a colación ese mismo autor inscripciones de madera de la mezquita cairota de Ibn Țūlūn; en una de ellas se lee amara bi-taŷdid al-ŷāmi ': «ordenó la reconstrucción». Como en el epígrafe del Cristo de la Luz, en otros fundacionales de Ifrīqiya figura $b a n n a \bar{a}^{\prime}$ con el sentido de arquitecto.

Desde luego la inscripción del oratorio toledano, descubierta por GonzálezSimancas en 1899, llegó a ese año bastante deteriorada, lo que motivaría la lectura de Amador de los Ríos, errónea a todas luces para el señor Ocaña quien, rectificándola, dio la lectura antes expuesta. Lévi-Provençal en 1925 medió en el tema dando un juicio bastante prudente: «quizá en 1899 el friso de ladrillo era más legible y menos desgastado que hoy», reconociendo de seguido que «entre la fotografía que vio en 1925 y el dibujo de Amador de los Ríos se aprecia que las grafías no ofrecen un trazado concordante». Ocaña Jiménez habla incluso de restauraciones en la epigrafía in situ hechas a gusto de Amador de los Ríos para satisfacer su tesis de «edificio restaurado»; ataques, creo, un poco excesivos.

Gómez-Moreno, en su último estudio de la mezquita del Cristo de la Luz, da jornada única de 999, en acuerdo con la inscripción fundacional, fábrica y orientación sureste, pero elude el Ibn Hadidì que leyó el señor Ocaña; sí lo menciona años más tarde Leopoldo Torres Balbás. En conclusión, la lectura de Ocaña ha prevalecido en todos los estudios posteriores y últimos sobre el oratorio toledano, pero no olvidando los infructuosos resultados al respecto de Lévi-Provençal. Amador de los Ríos sacó extremosas y disparatadas conclusiones en lo arquitec- 
tónico, viendo una mezquita fantasmal más grande que la actual, muy criticada por Gómez-Moreno y G. Marçais. En definitiva, el vocablo en litigio, borroso o deteriorado en el friso de ladrillo: «restauración» — ائجديد _ según Amador de los Ríos; «Ibn Ḥadīdī» — ابن حديدي - según Ocaña Jiménez. De toda esta exposición se desprende que en las inscripciones fundacionales árabes se emplean los términos bunyān, amara bi-bunyān, binā', aqāma; los tres primeros con la doble acepción construir y reconstruir o restaurar; tal vez el aqāma pudiera tener a veces el sentido de reerigir, en el sentido de poner en pie, hacer duradera o perpetuar (Luis Ma'lūf y Dozy; Kasimirski, Dictionnaire Arabe-Français. París MCMLX, II, 838: Dresser, inaugurer, installer, soulever, mettre sur pied, ressuciter). Aqāma está empleado en inscripción toledana que habla de nave — balāt — agregada en 1041 a mezquita, la de El Salvador de Toledo, según lectura de Codera y LéviProvençal. Otra nave añadida a mezquita, probablemente Santas Justa y Rufina, según lápida árabe, sin fecha y autoría, aparecida, fuera de su lugar de origen, en el muro de la calle de ese templo.

\section{ORIENTACIÓN LITÚRGICA}

El poner en discusión lo de la inscripción fundacional leída por Amador de los Ríos y el señor Ocaña, en lo que atañe a construir o reconstruir, viene de que el oratorio no está a nivel arqueológico o arquitectónico lo suficientemente explicado o interpretado en los autores hasta aquí citados y otros, según mi criterio. Me referiré en primer lugar a la orientación sureste, con declinación de la flecha más hacia el sur; orientación un tanto anómala para la segunda mitad del siglo x, en que es sabido se impuso por obra de los califas de Córdoba una orientación más separada del sur, es decir, flecha entre el sur y el este; así consta ya en la mezquita de Madīnat al-Zahrā', seguida de la cordobesa de la calle Rey Heredia y por lo que ahora se sabe la mezquita de al-Šifâ', en el arrabal occidental de Córdoba, mientras antes del califato las mezquitas se orientaban prácticamente al sur o suroeste en muchos casos, desde la Mezquita Mayor de Córdoba, seguida de la de Santiago en la misma ciudad, aquélla nunca rectificada; también muy en el sur la mezquita emiral de 'Adabbas de Sevilla. En este rápido ojeo de orientación litúrgica caben algunas mezquitas rectificadas, ya en la primera mitad del siglo x la mayor de Ceuta, posiblemente la de Almonaster de Huelva y la de Niebla. Desde luego, para los árabes la orientación del mihrăb o muro de qibla sería en todo tiempo objeto de controversias, recrudecidas en el Magreb con los almohades, que propugnaban orientación con declinación al sur. La orientación más al sur del Cristo de la Luz sería más propia de un antes del califato que de 
un después del año 929. Y en este punto es de consideración la mezquita toledana de las Tornerías, que se supone imitación del Cristo de la Luz, con orientación suroeste sin saberse a ciencia cierta si tal anomalía es propiciada por causas topográficas obligadas o porque ese oratorio es anterior al califato, cosa poco probable. Claro es que en el orbe mediterráneo se dieron otros casos en el siglo $\mathrm{x}$ de errónea orientación, por ejemplo, el oratorio de Sidi 'Alī 'Ammār de Susa dirigido a suroeste, cuando lo habitual en Ifrīqiya del siglo IX era sureste con declinación al sur, como en la mezquita emiral de San Juan de Córdoba, Cristo de la Luz, Alcazaba de Badajoz e incluso la supuesta mezquita toledana de San Sebastián y qibla de San Lorenzo, también toledana. Lo de mezquitas de Toledo con descarada orientación al sur pudiera ser síntoma local de vetustez; poco trabajo hubiera costado de haberse erigido en la segunda mitad del siglo $\mathrm{x}$ el Cristo de la Luz, de reducida escala, la imposición sureste califal, máxime si se tiene en cuenta que la mezquita de El Salvador de la ciudad la tiene, por tanto éste en principio oratorio califal, y lo mismo quizá referible a Santas Justa y Rufina, supuesto oratorio islámico a juzgar por un arco de la fachada de la calle, de herradura enjarjado tipo califal, con rebaje o rebaba en el intradós que se ve también en el arquillo del alminar cordobés de la calle Rey Heredia - Santa Clara—, el aliviadero del puente árabe de Guadalajara y los arcos del puente cordobés de Guadalbacar. Esa misma orientación sureste pudiera haber tenido inicialmente el templo de San Andrés. De toda esta exposición, se deduce en principio que en la ciudad del Tajo desde los inicios de la dominación musulmana primaría flecha litúrgica muy próxima al sur, como en la Córdoba emiral y en Ifrīiiya, error subsanado, aunque no siempre, en época califal en oratorios de nueva planta. Respecto a la capilla —así llamada por Gómez-Moreno- que yo denominé qub$b a$, de Belén del convento de Santa Fe, con cúpula de nervios entralazados al uso califal o del Cristo de la Luz, Delgado Valero la identifica con un oratorio de época taifa orientado a sureste con declinación al sur, orientación hipotética, aunque no descartable del todo: pudo ser qubba o pabellón de recreo de los palacios que había en toda esa parte, tradicionalmente atribuidos al soberano al-Ma'mūn.

\section{Planta EN CRUZ DE NUEVE TRAMOS IGUALES}

El segundo punto de reflexión es la planta del Cristo de la Luz y la de las Tornerías. Gómez-Moreno silenció ejemplos concretos de este tipo de planta de nueve espacios iguales detectados en Túnez y El Cairo que menciona Torres Balbás. Uno y otro autor dicen ser planta de origen bizantino. Con ello el tema a nivel planimétrico quedaba más o menos resuelto, sin que a ello de momento 
prácticamente nada aporte la arquitectura goda. Esta cuestión ha sido ampliada últimamente por G. King, que proporciona esos y otros puntuales ejemplos, como la mezquita de Balj en Afganistán estudiada por Golombek. Una vieja teoría, indemostrable arqueológicamente, dice que la planta del Cristo de la Luz estaría pisando otra goda del mismo tipo. Si esto fuera así, tendríamos resueltos muchos problemas; falta documentación al respecto, como reconoce Puertas Tricas, que de fuentes escritas anteriores a los árabes, extrae un templo en Toledo de la Santa Cruz, pero sin saberse si estaba en la ciudad o fuera de sus murallas. Lo lógico es que estuviera dentro, haciendo honor a esa titulación que pasó al Cristo de la Luz entre 1182 y 1186.

La planta de nueve tramos con pilares o soportes en número de cuatro, estructura por tanto bien trabada a todos los niveles, máxime si se cuenta con responsiones laterales en la mayoría de los casos y arcos adheridos a los muros, cuenta con ejemplos bizantinos en todo el orbe mediterráneo. Rivoira puso ya de manifiesto Santa Giaina, en Armenia, con planta de nueve espacios y pilares cruciformes. Los árabes adoptan para algunas mezquitas u oratorios-mausoleos parecida planta, en la de Bū Fațātā de Susa y en El Cairo el mausoleo de Šarīf Ṭabātabā, de la primera mitad del siglo X, estudiado por Creswell y comentado por Torres Balbás en su estudio del Cristo de la Luz. El oratorio cairota orienta a otro de Afganistán, el de Balj (siglo IX-X), con columnas adosadas a los pilares, responsiones y tres puertas por cada frente, menos en el muro de qibla, como en el Cristo de la Luz. En Turquía, parecida planta de oratorio del siglo Xv, de corte bizantino, en Edirne, según estudio de Siroux. Cabe mencionar la mezquita (siglo X) de la calle Rey Heredia o de Santa Clara de Córdoba, con grandes reformas cristianas, al parecer de nueve tramos y pilares en medio, cruciformes desde la base, aunque las últimas exploraciones realizadas en el templo revelan que el oratorio islámico no tenía ese número de tramos, según información de Antonio Almagro.

Se han mencionado edificios bizantinos y mezquitas con planta de nueve espacios iguales, todos ellos oficiales en el sentido de que están a flor de tierra y capacitados para funciones religiosas. Pero nos hemos olvidado de cisternas o aljibes hispanomusulmanes con la planta que nos entretiene. Cito el del patio de la Mezquita Mayor de Córdoba, de los tiempos de Almanzor; el de las Marmuyas, en Málaga (siglo IX-X); luego, otros muy tardíos: dentro de la Alhambra, el de debajo del Palacio de Carlos V, el de la Lluvia por encima de la Alhambra y el de las Tomasas del Albaycín de Granada. Es decir, la planta del Cristo de la Luz cuenta con ejemplos dentro de la infraestructura urbana o campestre hispanomulsumana ya del siglo IX-X. Es por tanto planta oficial y popular a la vez. No se descarta que hubiera en Toledo aljibes estructurados con nueve espacios, romános, godos o árabes. Semejante creencia pudiera ser avalada por la cisterna bizantina Majorum de 

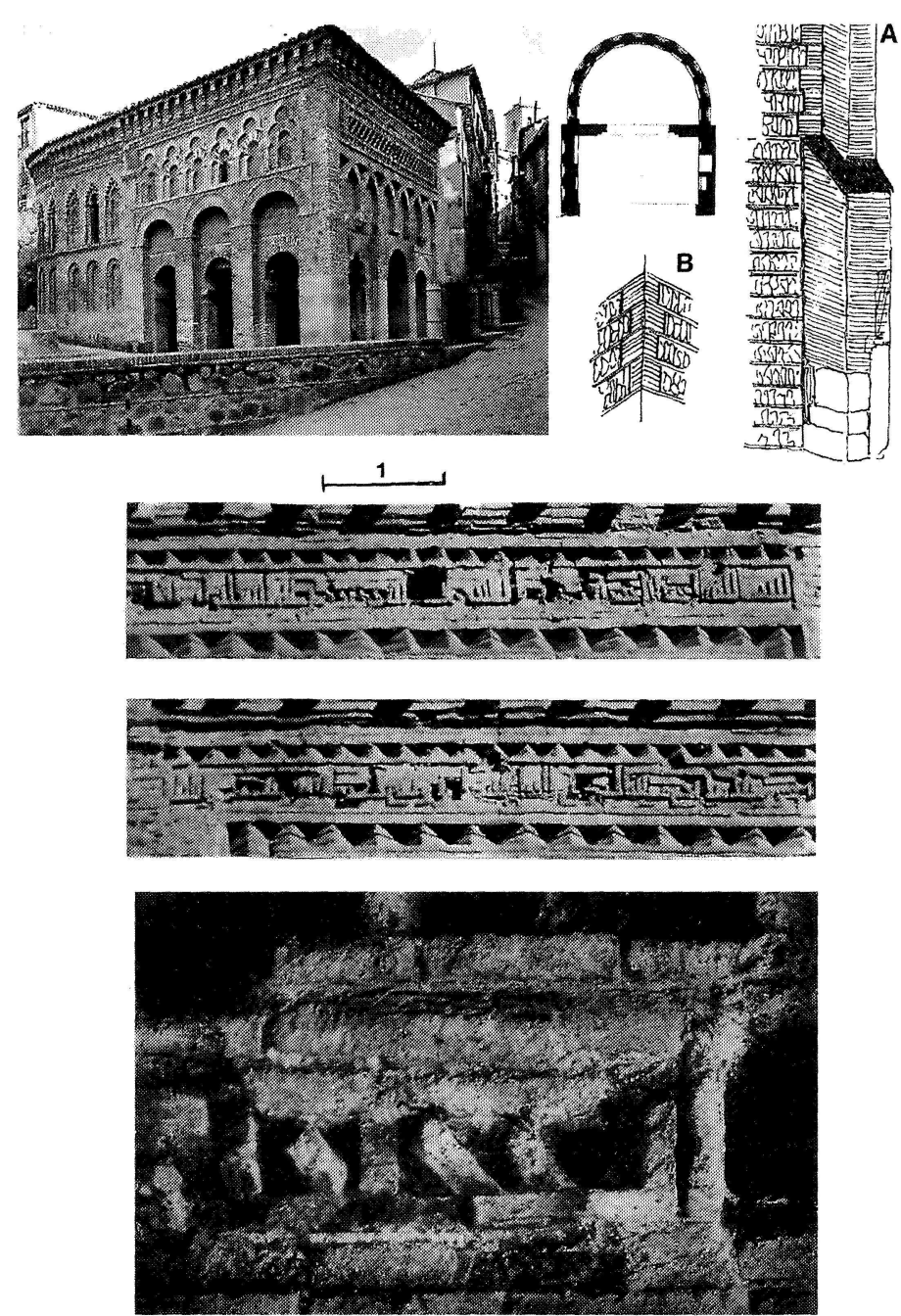

Figura 1. Mezquita del Cristo de la Luz, exterior y ábside mudéjar añadido en los siglos XII-XIII. Inscripción de la fachada de la calle, estado de la misma en 1949; y detalle de los vocablos ابن حديدى de grafía deteriorada (Ibn Ḥadīīi) precedidos de otro desaparecido (Ahmad), según Ocaña Jiménez. Los dos vocablos en fotografía de 1899 en poder de M. Gómez-Moreno. Texto según lectura de M. Ocaña Jiménez: «Basmala. Hizo levantar esta mezquita Ahmmad Ibn Hadīīi, de su peculio, solicitando la recompensa ultraterrena de Allāh [por ello], y se terminó con el auxilio de Allāh, bajo la dirección de Mūsa Ibn 'Alī el arquitecto y de Sā'ada, concluyéndose en muharram del año 390 (13 dic. 999/11 enero 1000 J. C.)»; A: ángulo suroeste del muro de qibla con mapostería y encadenado de ladrillo, con pilar de ladrillo adosado; B: aspecto del ángulo liberado del pilar de ladrillo. 

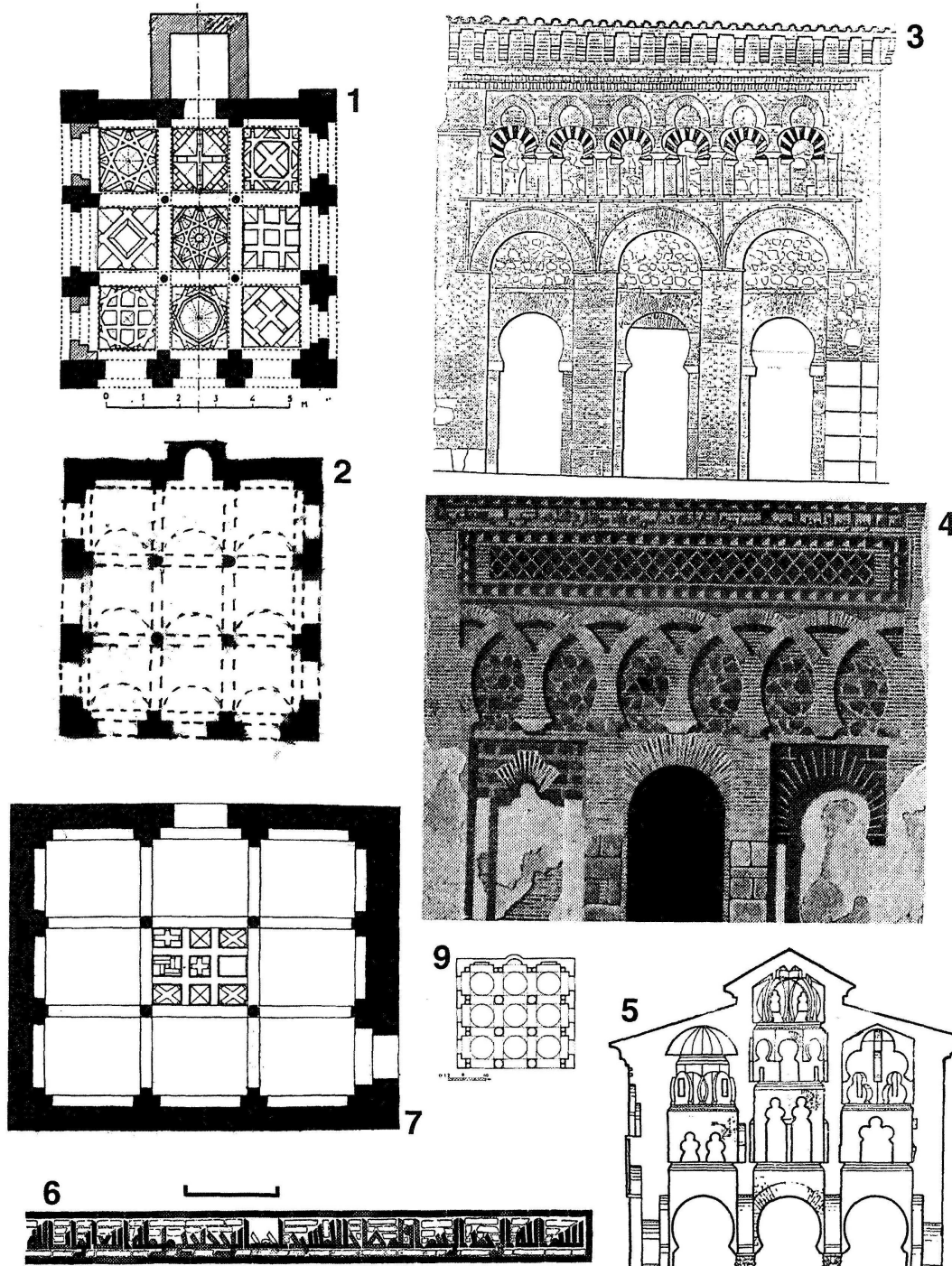

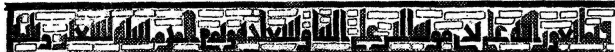

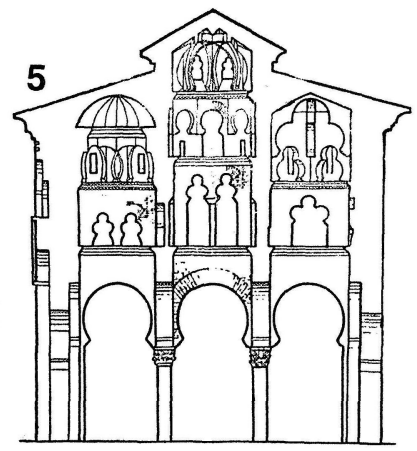

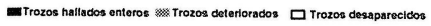

Figura 2. Mezquita del Cristo de la Luz; 1: Planta estado actual; 2: Planta de supuesta mezquita anterior a 999; 3: Fachada noroeste (Ewert); 4: Fachada de la calle (publicada por Amador de los Ríos, con el arco lobulado incompleto); 5: Sección, interior (GómezMoreno); 6: Inscripción de la fachada de la calle (Ocaña Jiménez); 7: Planta de la mezquita de las Tornerías, Toledo; 9: Mezquita de Balj, Afganistán. 
Cartago (nueve tramos y otras tantas bóvedas de aristas), precedente del aljibe de la mezquita cordobesa (Figura 4).

Mi criterio es que en Toledo pudo haber en las etapas preislámicas e islámica planta de nueve espacios con cuatro columnas o pilares cruciformes, que los árabes adoptaron para pequeños oratorios de barrio, que según Torres Balbás serían habituales en la ciudad. Esta tesis dejaría a las Tornerías sin el obligado precedente del Cristo de la Luz, debiéndose considerar como un oratorio más de la ciudad de planta muy popular desde antiguo; ese oratorio, que es mencionado desde el siglo XII, sería a juicio de Gómez Moreno y de Torres Balbás edificio mudéjar primerizo, si bien aquél lo incluye en su estudio del arte árabe de Ars Hispaniae III. En criterio de Delgado Valero y ahora también mío, encajaría mejor ese oratorio en la dominación musulmana de la ciudad. El paralelismo o binomio aljibe-mezquita a primera vista pudiera parecer poco académico, no menos que el binomio acueducto-arquerías de la Mezquita Mayor de Córdoba del siglo vIII. Si se toma este derrotero hay que hablar de cisterna-mezquita en el caso de Bū Fațātā de Susa, pues en realidad este oratorio es una síntesis de la cisterna árabe oriental de Ramla estudiada por Creswell, sin olvidar que el aljibe árabe de la casa de las Veletas de Cáceres — casi réplica del de Sofra, en Susa, estudiado por Lézine-, de cinco naves y arcos de herradura, tiene todo el aspecto de una mezquita de cinco naves que como tal la han estudiado voluntariosos tratadistas locales. Estructuralmente, el éxito de los nueve tramos entibados en todos los sentidos sale de las grandes cisternas bizantinas, de las que a veces son modélicas síntesis numerosas mezquitas turcas.

\section{ARCOS INTERIORES ADHERIDOS A LOS MUROS DE MAMPOSTERÍA}

La mezquita del Cristo de la Luz arroja una novedad para mí poco conocida en edificios mencionados y otros, que la ennoblece frente a las cisternas hispánicas conocidas. Me refiero a los arcos ciegos o murales de herradura interiores tendidos entre las pilastras de las responsiones, para anular empujes, arcos de escaso relieve incrustados en el muro de mampostería, repetidos en las Tornerías. Tal modalidad se ve en la torre-mihrāb de San Lorenzo de la ciudad, además de la iglesia mudéjar de San Andrés. Cabe aventurar precedente de ello en la mezquita mencionada de Balj y, aunque tardías, mezquitas iraníes de la zona de Ispahan estudiadas por Maxime Siroux: pongo como ejemplo la de Varkand. En la arquitectura islámica de Ifrīqiya, en muchos aspectos heredera de la tardorromana y bizantina local, se ven arcos adosados entre los pilares o columnas entregadas al muro: mezquitas de Qayrawān y de Susa, del siglo IX, con repercusión 
en el oratorio tunecino de al-Hawa, del siglo XIII. Respecto a cisternas preislámicas, cabe citar la bizantina de Hippona, en Argelia (Figuras 4, 3).

\section{PIEDRAS DECORADAS PREISLÁMICAS REUTILIZADAS}

El Cristo de la Luz tiene cuatro columnas en medio con fustes y capiteles godos, uno de éstos moderno, siendo ello notable arcaísmo para la segunda mitad del siglo $\mathrm{x}$ en que normalmente se erigen mezquitas con capiteles árabes labrados ex profeso, aunque en este punto nos falta adecuada documentación. Según criterio cordobés, una mezquita como la toledana que estudiamos, de la segunda mitad del siglo $\mathrm{x}$, debería tener en teoría fustes y capiteles labrados ad hoc; pero si la tomamos como oratorio precalifal, la reutilización de los soportes tiene lógica. Esto último avalaría la tesis de mezquita quizá emiral en planta y hasta poco por encima de los arcos de herradura del interior; es decir, mezquita de nueve tramos con bóvedas de aristas o de medio cañón, en todo caso baídas, como en las Tornerías, o de madera. Tales premisas dejan para la segunda mitad del siglo $\mathrm{x}$ las actuales cúpulas de nervios entrelazados tipo califal, en consonancia con las partes superiores de las fachadas exteriores que veremos más adelante.

Pero reaprovechar fustes y capiteles procedentes de edificios preislámicos en Toledo es hábito que debió darse también en época califal, si se acepta que la mezquita de El Salvador, con orientación preceptiva califal y arcos de herradura muy cerrados, fue erigida después del año 929. Esta mezquita tiene reutilizados pilastras, capiteles, quizá también cimacios, godos e incluso romanos. También Santas Justa y Rufina, con aquella misma o parecida orientación, deja ver pilastra goda bajo el arco de herradura comentado; capiteles y otras piedras godas se ven en San Sebastián — citada como templo cristiano en 1168 - de orientación S., mezquita, según propuesta de Gómez-Moreno, luego reconvertida. La clave del arco de herradura de piedra de la Puerta de Bisagra Vieja es una piedra decorada goda. Lógicamente, la masa ciertamente considerable de piedras godas labradas reutilizables impuso en Toledo una política o hábito casi oficial de reaprovechamientos que, al contrario de Córdoba, rebasa los límites de la segunda mitad del siglo x y llega a afectar a la etapa protomudéjar (iglesias de Santa Eulalia, San Román y San Andrés, torre de San Bartolomé y la de Santo Tomé). En la región toledana, la última reutilización de material godo se localiza en la iglesia de Almonacid, siglo XIV. Respecto a los fustes, es claro que en el Cristo de la Luz carecen de basas, modalidad iniciada en la mezquita cordobesa de 'Abd al-Raḥmān II con réplica en la mezquita de Madīnat al-Zahrā' y en la ampliación cordobesa de al-Hakam II. 

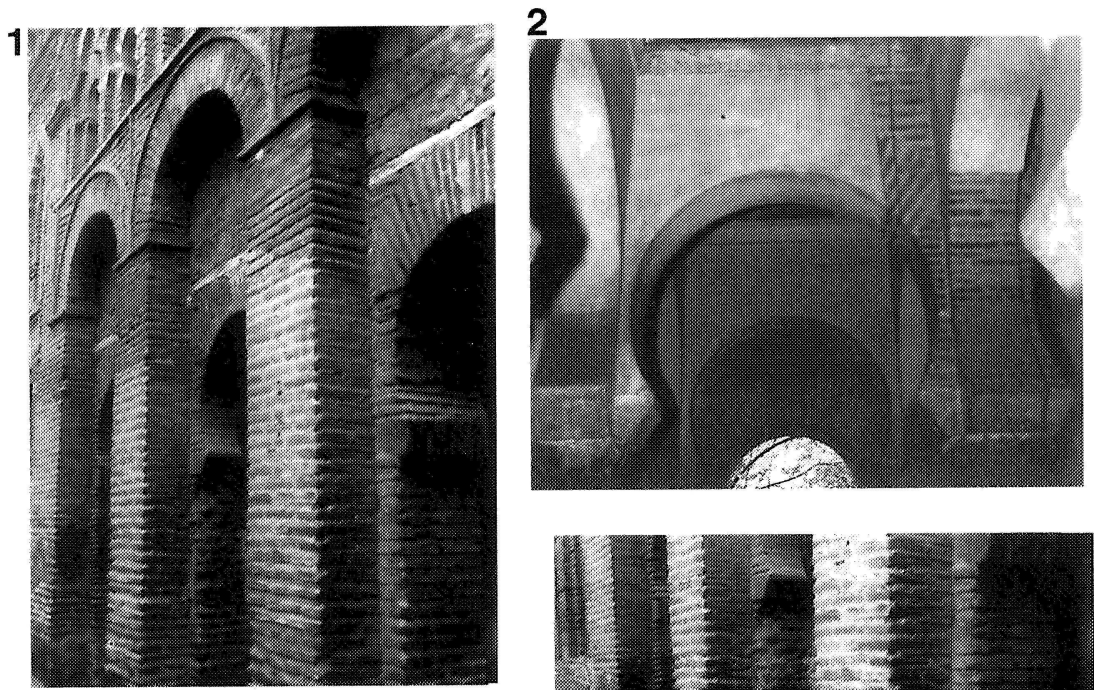

\section{3}
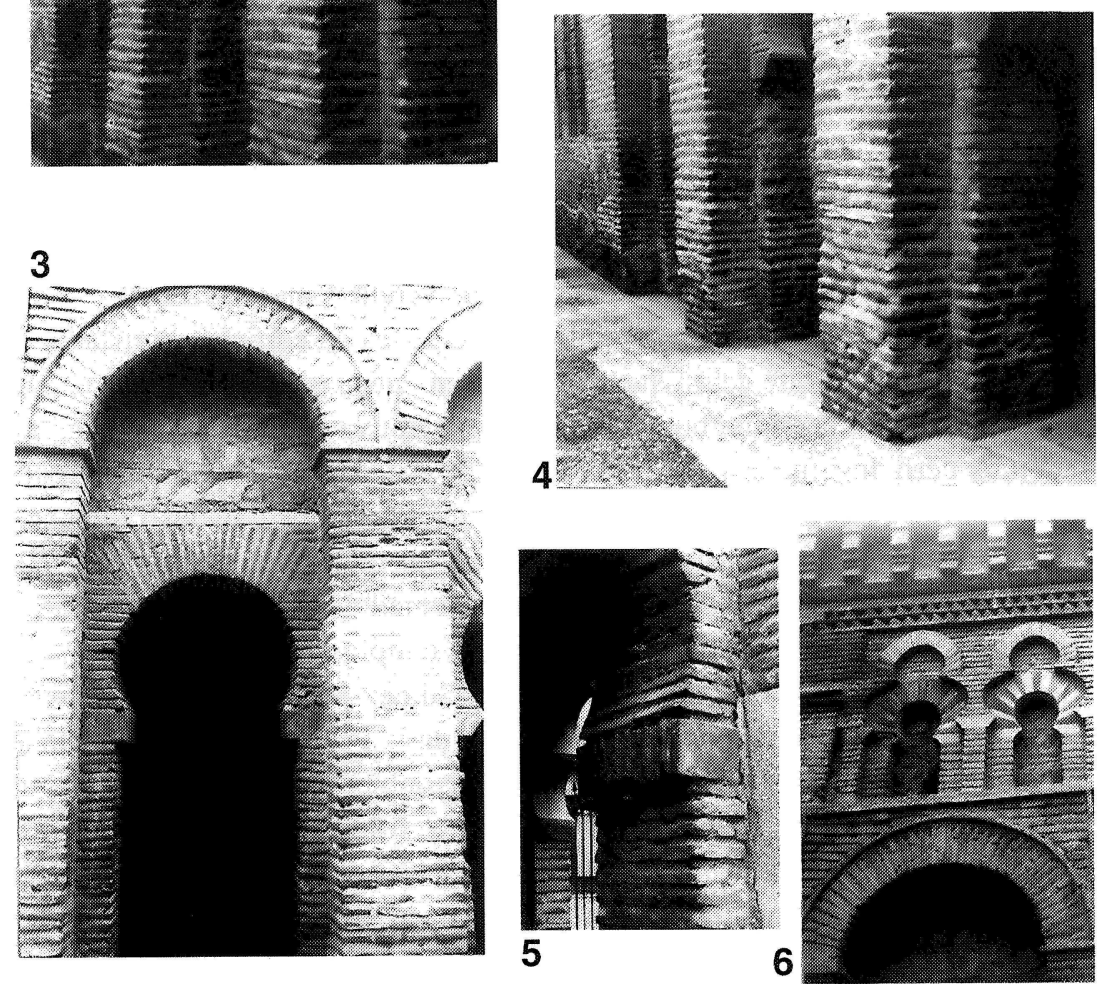

Figura 3. Cristo de la Luz de Toledo 1, 3, 4, 5, 6, fachada noroeste; 2: Arcos del interior; en la 6: Arquería superior, arcos de la izquierda sin restaurar en parte.

También en la mezquita mayor de Qayrawān del siglo IX se ven muchas columnas sin basas. 


\section{FACHADA NOROESTE}

La tesis de oratorio precalifal del Cristo de la Luz hasta la cumbre de los arcos de herradura inferiores del interior podría tener confirmación en la fachada noroeste, cuyos tres esbeltos arcos de medio punto - incluido el tradós- añadidos a nuestro juicio en las reformas de 999, nos darían la altitud aproximada del viejo oratorio; y de otro lado sugiere esquema en sección del mismo, es decir, arcos de medio punto de las supuestas bóvedas de medio cañón y arcos de herradura abajo, todo ello reflejado grosso modo en secciones del comentado aljibe malagueño de las Marmuyas o en la mezquita tunecina de Bū Fatātā. Si bien es igual de cierto que ese montaje de arcos de medio punto arriba y de herradura abajo pudiera provenir de la superposición de arcos — vía acueductos romanos - del interior de la Mezquita Mayor de Córdoba. Al hilo de ese trío de arcos de medio punto del Cristo de la Luz, llama la atención su adosado a lo que sería el muro del primitivo oratorio, muro de mampostería por el exterior y el interior, que en buena lógica no precisaría del reforzamiento exterior de los arcos de medio punto y sus potentes pilares. Esos muros de mampostería arrojan 0,70 metros de grosor suficiente para oratorio de reducidas dimensiones y bien entibado por dentro, como la mezquita de las Tornerías, que nunca tuvo el refuerzo exterior del Cristo de la Luz.

Acomodándonos a este argumento, se observa que los tres arcos de medio punto de la fachada noroeste serían mero pretexto para sostener la decoración añadida en la parte superior, y lo mismo ocurre en la fachada de la calle, con sendas pilastras destacadas que, junto con tres ménsulas excepcionalmente incrustadas en el muro, soportan todo lo superior. Reforzamiento el de los pilares que trabaja junto con las pseudotorretas de los ángulos del edificio, que son las que nos permiten hablar aquí de un viejo oratorio materialmente reforzado o forrado exteriormente por pilares y la decoración superior, todo de ladrillo menos la base de sillares antiguos aprovechados en los ángulos y pilares de la fachada de la calle, ahora repuestos, pero que llegó a dibujar Amador de los Ríos; tan sólo han llegado sillares antiguos en el pilar de la derecha del muro de qibla. A primera vista pudiera pensarse en oratorio con contrafuertes, o torrecillas al estilo de la mezquita de Córdoba o la de Madinat al-Zahrā', especie de quadribugium de carácter simbólico; pero en realidad tales refuerzos han sido añadidos como soporte de la decoración superior que no tendría el primer oratorio. Con tal planteamiento, parece que la mezquita recobra su lógica constructiva, porque de lo contrario, suponiéndola hecha toda en jornada única de 999, no tiene sentido ese excesivo reforzamiento exterior. Se pudo recurrir en ese año a solución más normal, cual es superposición de arcos dibujados en un mismo plano de la Figura 6, núm. 6. 
Quedan por subrayar los tres arcos de herradura inferiores de la fachada que comentamos, arcos de tres entradas efectivas que pudieron ser del primitivo oratorio. Roscas de ladrillo elevadas a 3,40 metros del suelo, con jarjas y prolongación de herradura en la mitad aproximada del radio en el arco central y convergencia de ladrillos dovelas en o por debajo de la línea de impostas. Los arcos extremos resultan ser ligeramente más estrechos, lo que insinúa protagonismo para el central, poco concordante con los arcos triples del califato cordobés; ese trío de carácter triunfal, repetido probablemente en la fachada de la calle, se ve en el siglo IX en las mezquitas tunecinas de Qayrawān y de las Tres Puertas. En los arranques de la herradura hay pseudoimpostas sin la clásica curva de la nacela o también perfil voladizo a bisel; tienen por el contrario moldura en ladrillo paralelepípeda o voladizo en vertical o en cuadrado, modalidad repetida en arco del otro extremo de la ciudad del puente Alcántara, insinuada en la puerta toledana de la muralla de Maqueda, también en el arco de aliviadero del puente de Guadalajara y en el arco de la entrada principal de la mezquita de Mahdiya (Túnez), y en la mezquita de El Salvador de Toledo; en lo visigodo, entre otros ejemplos, arcos de San Pedro de la Nave, seguidos de arcos de iglesias mozárabes (siglos IX-X). Es evidente el trazado muy irregular de los tres arcos de herradura con jarjas de la fachada noroeste que dejan un amplio margen para su data, no necesariamente de la segunda mitad del siglo $\mathrm{x}$.

Otra modalidad constructiva de la fachada son las rastras o maderos embebidos en la obra de mampostería, justo encima de los tres arcos de herradura antes comentados. Esas rastras se dejan ver también en los arcos de la fachada del patio de la Mezquita Mayor de Córdoba, rehecha en 958, reflejo sin duda de ancestral uso. El material lígneo es muy habitual en construcciones ifrīíes y magrebíes, desde el siglo VIII o IX, como dinteles, listones entrometidos en obra e incluso cimacios e impostas, aparte de emparrillados de madera del alminar de la mezquita de Córdoba, según dibujos de Félix Hernández, técnica ya empleada en muros de Constantinopla, Athos y Atenas, aparte de iglesias griegas de influencia bizantina. Volviendo al Cristo de la Luz, las rastras sobre arcos, a la vez que descargan, ejercen para mayor cohesión de la obra de albañilería, sometida quizá a empujes de las bóvedas, cualidades mecánicas propias de la madera en evitación de fisuras y resquebrajamiento del muro por cargas excesivas. En mi criterio, las rastras de la fachada del Cristo de la Luz trabajarían más con la fábrica del supuesto primer oratorio de abovedado, más potente que el actual, o de 999, de mero trámite decorativo. Ese mismo esquema, con rastras de madera, siguió en uso en otras obras islámicas aunque tardías, como el exterior de la torre de las Damas de la Alhambra. Es probable que las rastras del Cristo de la Luz continúen tras los pilares añadidos y es igualmente presumible que los tres arcos de herradura tuvieran antes de 999 guarnecido de estuco para el alfiz y 
quizá el trasdós, según se ve en la mencionada fachada del patio de la mezquita cordobesa.

Como confirmación de las dos supuestas jornadas constructivas, subrayo dos modalidades de albañilería. En primer lugar, las hiladas de ladrillo de los pilares exteriores supuestamente añadidos no guardan correspondencia o simetría con las hiladas de las jambas de los arcos de herrradura abiertos, y la argamasa de los tendeles de éstos contrasta ostensiblemente con la mezcla de cal y arena de las pilastras exteriores. Es decir, una y otra obra no están trabadas, la exterior adosa en la interior dejando entrever dos etapas. Esto aparte, remito al añadido o reforzamiento en 958 de las pilas y arcos de la fachada del patio de la Mezquita Mayor de Córdoba (Figura 6, núm. 7). Se advierte que el ladrillo del Cristo de la Luz, empleado en todo el edificio, es el 26 o 27-17-4, dimensiones generalizadoras, vistas en el interior y la supuesta obra añadida de 999 , lo que no es grave obstáculo para admitir aquel refuerzo añadido, dado que sería normal que tales dimensiones se mantuvieran vigentes en los períodos emiral y califal toledanos, máxime si se tiene en cuenta que las mismas dimensiones y otras muy parecidas se conservan en algunos edificios mudéjares del siglo XIII (San Juan de Ocaña y Torre de Móstoles). Un detenido examen in situ de las dimensiones del Cristo de la Luz nos llevaría a admitir que el ladrillo no respondería a módulo o molde único, como en Madīnat al-Zahrā' que, pese a no ser ladrillera, arroja patrón con tres o cuatro variantes de ladrillo no muy acusadas, siempre la latitud equivalente a los $2 / 3$ de la longitud, como en el Cristo de la Luz, según receta antigua en lo romano. Es advertencia, trasladándonos a la Sevilla del siglo xII, que los ladrillos de la Giralda se dejan ver dos siglos después en torres mudéjares de la ciudad. Respecto a los esbeltos arcos de medio punto del noroeste cabe destacar la moldura de trasdós y alfiz realizada con ladrillos destacados y puestos de canto, inédito en lo hispanomusulmán muy anterior, aunque visualizado en algunas puertas y arcos de puentes tardorromanos, en Toledo presentes, además de esa fachada, en la de la Puerta de Bisagra Vieja, arco de San Miguel y ventanas de las torres de San Andrés, Santiago del Arrabal y San Bartolomé. Se trata de la traducción al ladrillo de arcos omeyas nuestros con molduras de trasdós y alfiz.

\section{EL PROBLEMA DE LAS PUERTAS DE ORATORIO}

Los tres arcos de herradura de la fachada noroeste, supuestas entradas efectivas del primitivo oratorio, son una llamada de atención para explicar otras entradas. Esos arcos inicialmente no tuvieron gorroneras para los quicios de puerta de madera. Puertas, por tanto, permanentemente abiertas. Un oratorio de reducidas 

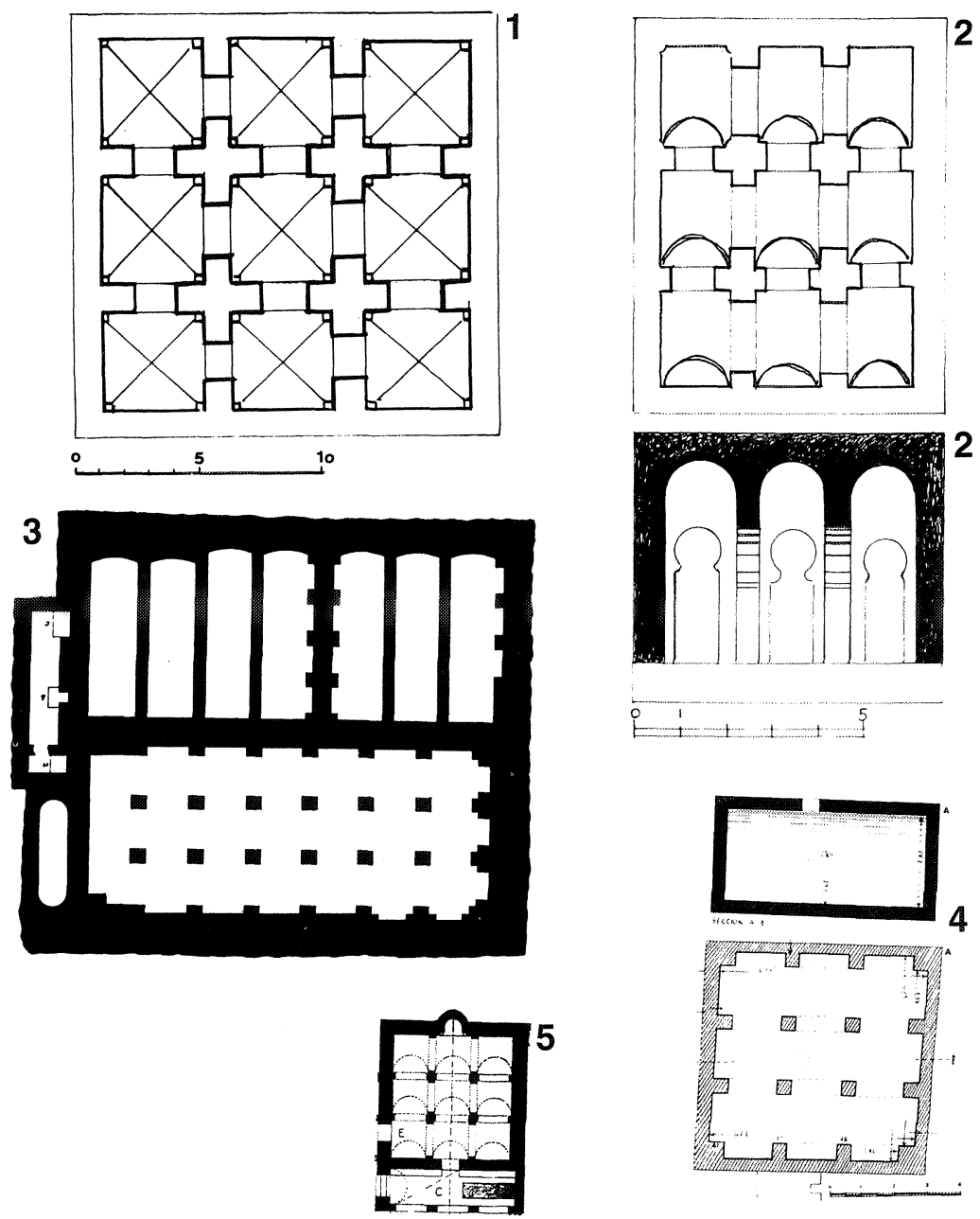

Figura 4. Plantas de aljibes: 1: Árabe del patio de la Mezquita Mayor de Córdoba; 2: Despoblado de las Marmuyas, Málaga; 3: Cisterna bizantina de Hipona (S. Gsell); 4: Aljibe de debajo del Palacio de Carlos V, Alhambra; 5: Mezquita de Bū Fațātāa (Creswell).

dimensiones como es el que estudiamos, con capacidad no superior para 50 fieles, debió estar abierto precisamente por el lado noroeste, donde habría explanada, un lugar de postración al aire libre - muṣallà-. Quizá este mismo planteamiento tendría inicialmente la mezquita qayrawaní de las Tres Puertas, como el Cristo de la Luz, abierta en el eje norte-sur. Es sintomático que en la reforma de 999 fueran respetadas las tres puertas del noroeste, que seguirían abiertas sin hojas 
de madera. Respecto a la fachada de la calle, parece claro que sus tres puertas fueron reformadas en 999 siguiendo pauta califal, pero nada impide imaginar allí primitivos vanos sin hojas de madera semejantes a los de la fachada noroeste que pudieron darse también en la del este, reformada al acoplarse en ella el ábside mudéjar. Tendría el Cristo de la Luz inicialmente aspecto de qubba o capilla mortuoria abierta por los cuatro costados. De aceptarse tal programación primitiva de puertas, en tres fachadas y simétricamente dispuestas, tendríamos una réplica de los oratorios mencionados de El Cairo y el afgano de Balj, sin que sea fácil o permisible establecer conexiones y prioridad cronológica en uno y otro sentido. La interpretación más verosímil del oratorio toledano es que nació antes de 999 con nueve arcos de puertas, funcionando el edificio como una mușallà, como han expresado otros autores, más que como oratorio privado. En ese año se modificarían las puertas de la fachada de la calle — rehecha modernamente la central—, en el siglo x probablemente más ancha y alta la de en medio que las extremas; la de la derecha con arco de herradura de dovelaje completo al estilo califal, rebajada algo respecto al paramento de encima formando el trasdós a modo de escalón que se advierte en la mezquita cordobesa de la calle Rey Heredia, la puerta militar de Maqueda, el puente de los Nogales de Córdoba e incluso en el arco andalusí de la mezquita de Ibn Țülūn. Arcos de dovelaje completo se dan inicialmente en Madīnat al-Zahrā' y Mezquita Mayor de al-Hakam II de Córdoba, la puerta mencionada de Maqueda y la puerta principal del castillo califal de Gormaz. La otra puerta presenta un arco de cinco lóbulos, el lóbulo superior de ladrillo puesto de canto y los restantes recortados en losetas de barro vistas de plano, acotadas por finas cintas, también de barro, en el sentido horizontal y vertical, formando especie de aparejo de aspecto bizantino o «cloisonné», inédito hasta ahora en Toledo, pero de amplia usanza en la arquitectura castrense mudéjar, así como en Málaga. La ausencia de simetría y paridad en las dos puertas extremas lleva a pensar si la puerta izquierda se añadiría después de 999, quizá en etapa protomudéjar. Arcos lobulados recortados en placas o losetas vistas de plano figuran en la espadaña del convento de Santa Isabel la Real, del siglo XIv. Pero los cinco lóbulos de filiación califal se ven en la parte superior interior del Cristo de la Luz, y a continuación los de nichos bajos de la toledana capilla mihrāa de San Lorenzo. Respecto a gorroneras de piedra, lo habitual en la Córdoba del siglo x es la piedra con nacela en el vuelo, a la que se añade baquetón cilíndrico; en Toledo esa forma sólo se ve en la puerta ciega del templo de San Román (Figuras 5, 6). En el revestimiento de 999 de la fachada de la calle que analizamos, cobran protagonismo los arcos de herradura entrelazados que dan lugar a arquillos de herradura estrechos y apuntados en serie, fórmula -inicialmente goda en arcos entrelazados de medio punto- que, inaugurada en las fachadas de al-Hakam II de la Mezquita Mayor de 

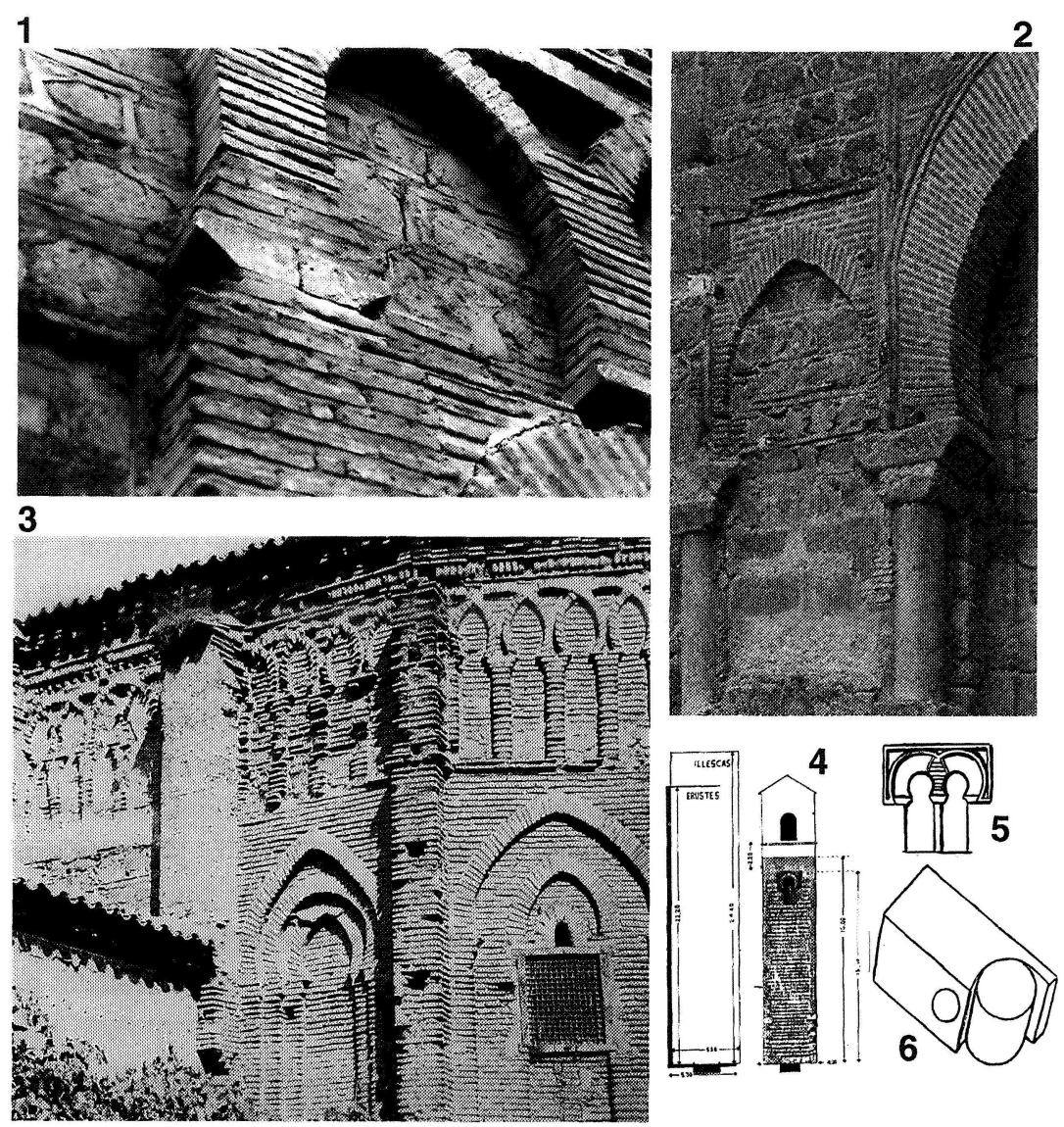

Figura 5. 1: Fachada de la calle, Cristo de la Luz; 2: Puerta de Bisagra Vieja, Toledo; 3 : Iglesia de Santa Fe, Toledo (en 1 arquería adosada al muro por simple contacto; 2 y 3 , arcos cuyos ladrillos penetran en el muro del mismo material o de mampostería); 4: Torrealminar de San Andrés, Toledo, al lado Torres mudéjares más monumentales; 5: Ventana de las torres-alminares de Santiago del Arrabal y de San Bartolomé, Toledo; 6: Gorronera de piedra de la iglesia de San Román, Toledo; probablemente de edificio islámico.

Córdoba, los mudéjares toledanos instalan en muchas de sus construcciones. Ese entrelazado omeya de arcos de ladrillo en el Cristo de la Luz - visto con ese mismo material en la alberca cordobesa de la huerta de Cañito de María Ruiz-, es simplemente adosado, no incrustado, en la mampostería, según vimos en la fachada noroeste, lo que es bastante irregular en edificios de ladrillo de jornada única (ver Figura 5). 


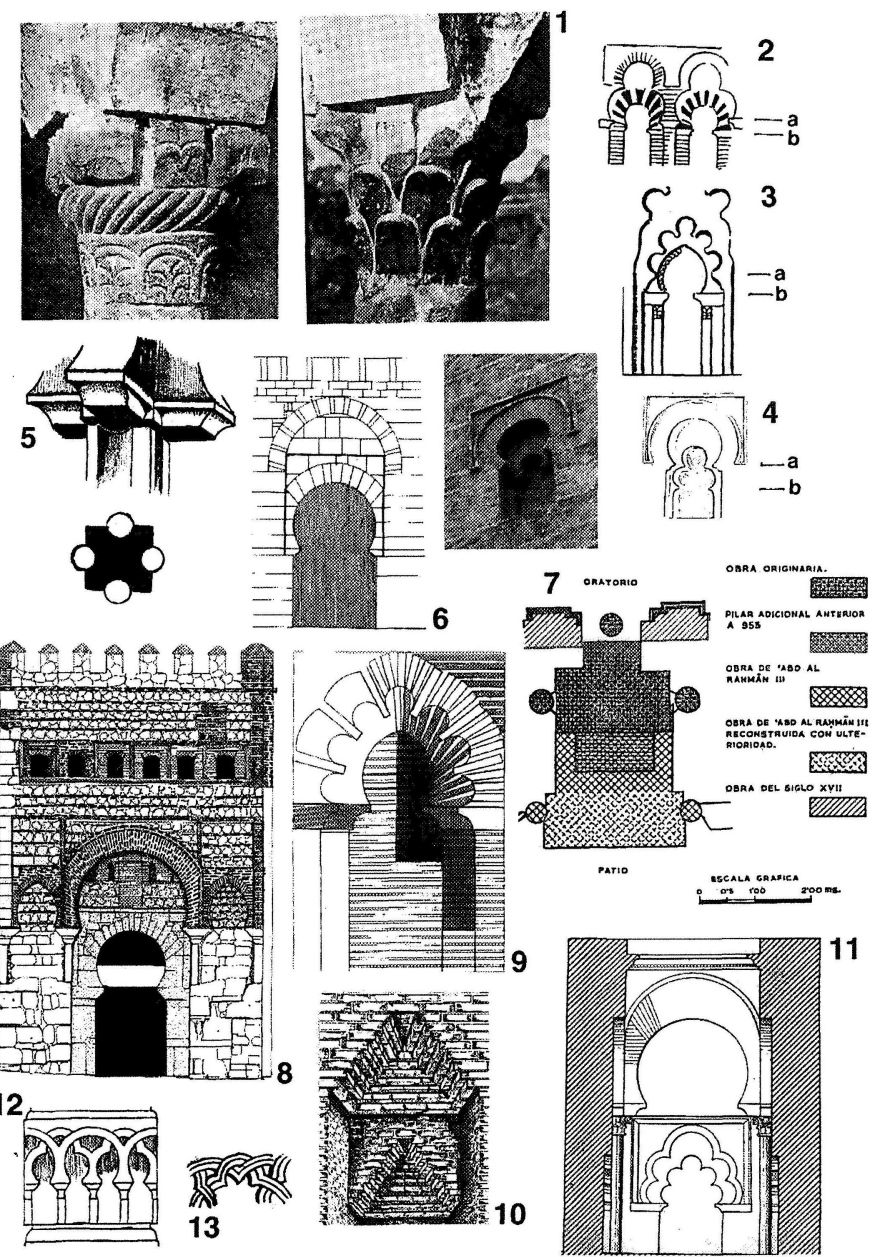

Figura 6. 1: Dos capiteles preislámicos, Cristo de la Luz; 2: Arcos superpuestos con dos niveles de impostas, fachada noroeste; Cristo de la Luz; 3: Superposición de arcos con dos niveles de impostas, fachada mudéjar de San Andrés, Toledo, siglos XII-XIII; 4: Arcos superpuestos con dos niveles de impostas, torre alminar de San Bartolomé, Toledo; 5: Cimacio de planta cruciforme, baños de Córdoba, siglo x; 6: Solución de arcos superpuestos en un mismo plano, puerta de muralla del Alcázar de Sevilla, siglos X-XII; 7: Obra califal añadida a obra emiral, fachada del patio, Mezquita Mayor de Córdoba (según Félix Hernández); 8: Puerta de Bisagra Vieja, Toledo, siglos X-XI; 9: Arcos superpuestos con un mismo nivel de impostas, solución almohade, mudéjar toledano, siglos XIII-XIV; 10: Techo árabe-mudéjar de torres toledanas; 11: Torre-mihrāb de San Lorenzo, Toledo, siglos X-XI (según GómezMoreno); 12: Friso del muro de qibla, Cristo de la Luz; 13: Decoración de basa, procedente del convento de las Reinas, Toledo, siglo XI. 


\section{ARCOS DE HERRADURA DEL INTERIOR}

Los arcos de herradura en número de 12 del interior, todos con jarjas, tienen trazas bastante irregulares, advirtiéndose que las prolongaciones de la herradura fluctúan sensiblemente en todos ellos, desde la mitad del radio, ya empleado en Córdoba en el siglo IX, a modulaciones un tanto extrañas que dan arcos relativamente abiertos y casi siempre con convergencia de dovelas por debajo o en la línea de impostas, todo ello no muy acorde con arcos árabes de la segunda mitad del siglo x. En este sentido, tratándose de arcos de piedra y sobre todo de ladri1lo, es difícil establecer un canon fijo de una a otra centuria, y ello referido a arcos de herradura de otros lugares adscritos a los siglos IX y $\mathrm{X}$, en los que las prolongaciones ultrasemicirculares de $1 / 2$ y $1 / 3$ y otras modulaciones no constituyen precisamente norma o canon de una y otra centuria. Gran parte de los arcos de herradura hispanomusulmanes han sido interpretados arbitrariamente o se les han puesto prolongaciones o peraltes a ojo. Pese al encomiable entusiasmo demostrado por Gómez-Moreno, Camps Cazorla, Íñiguez Almech, Félix Hernández, Ch. Ewert y Caballero Zoreda en la sistematización del modulado de los arcos de herradura que Delgado Valero ha aplicado al todo Toledo árabe, las conclusiones obtenidas son referenciales u orientativas más que canon de obligada aplicación en esta o aquella época. Los peraltes $1 / 2$ y $1 / 3$ se dan reunidos a veces en obras del siglo $\mathrm{x}$ y otras modulaciones de difícil catalogación. Por último, todos los autores que se han ocupado del Cristo de la Luz aceptan que los arcos interiores iban estucados hasta y por encima de la cornisa en nacela del primer cuerpo.

\section{CIMACIOS CRUCIFORMES}

Sobre los capiteles visigodos asientan cimacios de piedra en forma de cruz que en Córdoba se insinúan en la ampliación de al-Hakam II de la mezquita metropolitana: cimacios de dos vuelos a los que se añaden los dos exiguos tenantes de las pilastras de arcos superiores, según estructura muy distinta a la del Cristo de la Luz. En las ruinas de Volubilis y otros yacimientos antiguos, hay pilares cuadrados con cuatro medias cañas adosadas, permitiendo imaginar arriba cimacios cruciformes para recibir cuatro arcos; lo mismo en el tepidarium de las termas de Tuburbo Maius, en Túnez, modalidad que se ve en el apodyterium de los baños al parecer califales de la cordobesa plaza de los Mártires y en los baños posteriores de Jaén y de Mallorca en lógica constructiva antigua. Así las plantas de nueve tramos conllevan pilares cruciformes o columnas con cimacios 
de cuatro vuelos. Los cimacios del Cristo de la Luz tienen perfil de nacela en curva apenas perceptible, siguiendo pauta romana-bizantina, si bien el cimacio omeya, nuestro más normal, tiene perfiles inclinados o corte de bisel impuesto en lo godo, en Córdoba y Madīnat al-Zahrā’; en el alminar cordobés de San Juan (siglo IX), por ejemplo, ya hay cimacios con curva de nacela, repetida en ménsulas de las puertas de Deanes y de San Esteban de la mezquita cordobesa, también de la novena centuria; con ligera curva fue labrada la ménsula del arco árabe de Santa Justa y Rufina. Incrustadas en el muro y como soporte de los arcos decorativos entrelazados de la fachada de la calle del Cristo de la Luz figuran ménsulas con curvas pronunciadas. Es muy probable que en Toledo se estabilizara desde el siglo IX el cimacio o ménsula de vuelo en curva antes que el biselado de mayor ascendencia califal; éste se ve en ventanas superiores lobuladas del interior del Cristo de la Luz y en el arco de piedra de la Puerta de Bisagra Vieja. En la mezquita cordobesa de al-Hakam II hay tendencia a alternar los dos tipos de vuelos; en obras enteramente de ladrillo se impuso la curva, a partir de la supuesta mezquita de San Sebastián y Santa Eulalia. En resumen: si la anterior exposición es acertada, no parece claro que todos los cimacios del Cristo de la Luz sean del año 999.

\section{EL MURO DE QIBLA Y EL MIHRĀA}

El muro suroeste de qibla es el único que enseña al exterior fábrica de mampostería encintada completa, a nuestro entender de la primera mezquita —on esquinales de ladrillo vistos en el ángulo pegado al ábside cristiano (Figura 1, A y B)— por quedar libre de las modificaciones introducidas en 999 . A los extremos se ven como colgadizo desalineado las caras de los contrafuertes de ángulo. Llegó el arco de herradura enjarjado del mihrāan, no así el nicho que a juicio de Gómez-Moreno era de planta cuadrangular, según exploraciones realizadas en el subsuelo; era un cuadrado del tamaño aproximado de un tramo del interior, cuadrado exterior de 2,80 metros de lado, que para Torres Balbás correspondería a presbiterio al ser consagrada inicialmente la mezquita al culto cristiano, en 1182 $\mathrm{o}$ antes. Aunque al-Andalus presumió de mi hräab-s cuadrados ya en el siglo x, parece excesivo de tamaño ese supuesto mi hrāab toledano y no se descarta del todo que en lugar de presbiterio hubiera torre de imprecisa cronología - 2,61 y 2,90 metros de lado tienen los alminares de San Sebastián en Ronda y de la Alcazaba de Jerez de la Frontera, y el mihrāa b cuadrado de Almería, 1,90 de lado-.

Lo normal para los tres primeros siglos de al-Andalus sería nicho-mihrāa b semicircular con proyección cuadrada al exterior, de ínfimo tamaño al parecer, así reconocido en la mezquita emiral cordobesa. Esos nichos miḥrāb-s, a veces 
ultrasemicirculares, del siglo $\mathrm{x}$, han sido reconocidos en oratorios de Almonaster de Huelva, rábitas de las Dunas de Guardamar en Alicante y últimamente en el despoblado de Vascos (Toledo). Es posible que ese tipo de nicho de ascendencia oriental, prácticamente empleado por sistema en Ifrīqiya aglabí (mezquita de Bū Fatātāā de Susa), se diera inicialmente en el Cristo de la Luz. Dentro de Toledo, es peculiar cómo se vio en San Lorenzo el mihrāa b la vez que alminar, dando pie ello a reflexiones en torno al caso del Cristo de la Luz; pero es de creer que este oratorio no disponía de alminar, como los al parecer privados de las Tres Puertas de Qayrawān y el Bū Fatạtạa de Susa. En el Cristo de la Luz se añadiría en 999 el friso sobre el arco del mihrāb de arcos de herradura mezclados con otros de tres lóbulos en el que Gómez-Moreno vio capricho parejo a lo posterior de la Aljafería de Zaragoza (Figura 6, 12).

\section{Cúpulas Nervadas}

Sobre las cúpulas con arcos o nervios entrelazados del Cristo de la Luz de 999, reproducciones en miniatura cinco de ellas de las califales de la Mezquita Mayor de Córdoba, coinciden todos los autores, salvo Golvin, que parece que se inclina a admitir modalidad constructiva local toledana antes que cordobesa. Novedad de las cúpulas más complejas de ascendencia cordobesa, es el peralte de herradura de los nervios entrelazados, repetidos en la cúpula de la capilla o $q u b b a$ de Belén del convento de Santa Fe. Respecto a la excesiva esbeltez interior del Cristo de la Luz - 10,30 metros hasta la cúpula central—, la subrayó ya Gómez-Moreno, cinco veces el ancho de cada tramo. Es exceso inédito en la arquitectura islámica bastante por encima de los tabernáculos de delante del mih$r a \bar{b} b$ de la Mezquita Mayor de Córdoba con altura de dos a tres veces el ancho del tramo. Es probable que esa anómala altitud en Toledo sea un reflejo más o consecuencia de las dos jornadas constructivas que venimos defendiendo, la de 999 forzada e inédita tanto en la altura del interior como en el expresado reforzamiento del exterior.

\section{Arcos lobUlados}

El Cristo de la Luz enseña por vez primera en la ciudad arco de tres lóbulos inspirados en los de Madīnat al-Zahrā' y de la Mezquita Mayor de Córdoba de al-Hakam II y de Almanzor. El de tres lóbulos figura en el friso superior de la fachada noroeste dando cobijo a otro de herradura sencilla: superposición de 
arcos con sus respectivas impostas a distinto nivel, una modalidad transferida de los lucernarios de delante del mihrāa de la Mezquita Mayor de Córdoba que trasciende a una de las ventanas de la torre de San Bartolomé - aquí el arco montante es el de herradura-. En el interior del Cristo de la Luz, sencillos y doblados, en el segundo cuerpo, se repiten ventanas de tres y cinco lóbulos. Sobre el arco de cinco lóbulos de la puerta de la izquierda de la fachada de la calle, ver apartado 7. La mezquita de las Tornerías tiene arcos decorativos de tres lóbulos tradosados. El arte mudéjar casi desconoce el arco de tres lóbulos.

Volviendo a los arcos superpuestos con el lobulado encima e impostas en diferente nivel, el último ejemplo toledano es el de la mencionada portada de la iglesia de San Andrés (siglos XII-XIII) posiblemente relacionado con lo almorávide y lo almohade, alminar de Tìt de Marruecos y la Giralda de Sevilla, últimos ejemplos de tal modalidad dentro de dominio islámico. Diferente es la superposición de arcos con el lobulado encima y las cuatro impostas a un mismo nivel, por lo general arcos de trazas apuntadas inauguradas en la mezquita cordobesa de Almanzor. Figura tal superposición por vez primera en el alminar de la mezquita de la Kutubiyya de Marrakech siendo de muy probable influencia almohade los numerosos ejemplos de esa modalidad detectados en ábsides mudéjares toledanos, el añadido del Cristo de la Luz e interior de San Román, de la primera mitad del siglo XIII (Figura 6).

\section{LADRILLO Y MAMPOSTERÍA}

La fábrica de ladrillo y mampostería es una cuestión básica en la interpretación del Cristo de la Luz y, en general, del arte medieval toledano. Tema éste amplio y complejo que abordo más detenidamente en mi Tratado de arquitectura hispanomusulmana. II. Ciudades y fortalezas. De entrada, es obligado separar esos dos conceptos o procedimientos constructivos. La tesis de Gómez-Moreno es que el ladrillo en Toledo, la construcción y decoración de ese material, resultó ser una importación o sugerencia árabe oriental, concretamente de Mesopotamia donde los soberanos abbasíes lo emplean sistemáticamente y con él se obtienen arcos y ventanas lobuladas - Samarra, Ujaydir y Raqqa - H. Terrasse escribió que la técnica del ladrillo en Toledo pudo tener relación con el arte abbasí. No hizo Gómez-Moreno distingos entre el ladrillo y la mampostería, ésta occidental y de viejo cuño hispanorromano, según se advierte en las ruinas de Mérida y la misma Ampurias, entre otros ejemplos. Sobre la misma, Torres Balbás escribió que este procedimiento - mampostería con verdugadas de ladrillo- puede ser local, frecuentemente empleado en la arquitectura romana de los últimos tiempos imperiales -modernamente se le llama opus mixtum. 
Como vimos, el ladrillo en el Cristo de la Luz tiene dimensiones 26 o 27-174 , latitud $2 / 3$ de la longitud, proporción antigua vista en yacimientos romanos peninsulares y en Madīnat al-Zahrā', si bien aplicada a ladrillos de mayores dimensiones que el del Cristo de la Luz. Aquí las fajas de mampuesto dan entre 0,25 y 0,30 de altitud, entre verdugadas sencillas de ladrillo repetida en la torre exterior de Bāb al-Mardūm, los baños árabes de la ciudad, algo de paramento del interior de Bāb al-Qanțara y el puente del mismo nombre, la parte superior de una torre califal de la Alcazaba de Talavera y las torres toledanas de Santiago del Arrabal, San Bartolomé y San Andrés; es mampostería también registrada en lo romano de Mérida y otros yacimientos antiguos. En lo mudéjar a partir probablemente del siglo XIII, las fajas de mampuesto acusan más altitud en ascensión progresiva. Respecto a lo visigodo, Puertas Tricas cita fuente de escritores del siglo VII aludiendo al parecer al ladrillo: «se llaman lateres porque son alargados y se hacen con moldes o cuatro tablas; también se les llama laterculi». Ya en el siglo viII y el IX, mencionan las fuentes árabes ladrillos bajo el nombre de $a l-t \bar{u} b$, a veces țüb labin — secado al sol— que pudo confundirse con țüb aŷur - pasado por el fuego, casos referidos a Córdoba (Maqqarī) y Badajoz (Bayān II). Desde luego nuestros ladrillos dan la espalda al ladrillo abbasí y de Qayrawān, por lo general biperales. Los focos de construcciones ladrilleras musulmanas con presencia de mampostería encintada son Badajoz, MálagaGranada, Ceuta-Magreb y Toledo como más principal que trasciende a todo el mudéjar castellano; de Roma a lo bizantino aclimató el ladrillo, al que los árabes supieron tratar como material noble, visto con testimonio bien elocuente en el Cristo de la Luz. El interrogante en Toledo es si el legado monumental godo, que dispuso en la ciudad de 13 templos de los que procederán numerosos fragmentos de piedras decoradas y advocaciones aún vigentes en templos mudéjares o mozárabes - siete-, con constatada penuria económica, era todo de sillería, o hemos de admitir fábricas ladrilleras preislámicas en la ciudad como las del Cristo de la Luz.

\section{REFLEXIONES Y RESPUESTAS FINALES A MODO DE CONCLUSIÓN}

Los anteriores apartados referidos al Cristo de la Luz descansan en la falta de coherencia advertida entre el exterior y el interior, visto el edificio de abajo arriba, sin clarificar en la inscripción fundacional leída por Ocaña Jiménez, todo contemplado desde un punto de vista arqueológico o arquitectónico. En lo que a inscripciones árabes fundacionales se refiere, parece comprobado que monumentos antiguos islámicos se los han arrogado determinados emires o sultanes cuando en 
realidad éstos se limitaron a restaurarlos o a actualizarlos, pongo por caso la puerta de San Esteban de la Mezquita Mayor de Córdoba y, como caso más extremo, la Puerta del Vino de la Alhambra, vieja entrada que Muhammad V actualizó en la segunda mitad del siglo XIV haciendo poner en ella el epígrafe de yeso del exterior, donde se dice que él es el autor o mandatario que la construyó. En esta línea, parece incuestionable que el Cristo de la Luz, tras el año 999, era o se presentaba como un nuevo oratorio, quedando todo lo anterior que pudiera haber habido allí desdibujado o palidecido. Las mezquitas en todo tiempo se reforman, amplían o actualizan, siendo un título de honor para quien tiene poder para hacerlo. Quizá el ejemplo más expresivo de todo ello sea la desaparecida mezquita mayor de Ceuta, que desde el siglo $\mathrm{x}$ conoce todo tipo de restauraciones y adiciones. Como se ha visto, en Toledo fueron ampliadas con nueva o nuevas naves la mezquita de El Salvador y posiblemente la de Santas Justa y Rufina, y otra en 1042; la Mezquita Mayor de esta ciudad, que conoció obras de actualización ya en el siglo IX referidas al alminar (Ibn Hayayān) - Muhammad I en 871 mandó reconstruirlo por estar arruinado o semiarruinado-, debió recibir todo tipo de influjos cordobeses califales, porque sería baladí suponer que lo más selecto del arte cordobés de alHakam II fuera a parar tan sólo a modestos oratorios de barrio como el Cristo de la Luz. Respecto a si en esta mezquita se aprovechó parte o al menos planta de santuario godo allí mismo emplazado, con los testimonios arquitectónicos in situ no se puede aclarar nada, porque del suelo para arriba la fábrica es íntegramente islámica; de manera que en este punto lo godo es mera presunción, limitándonos como síntesis de toda esta cuestión a reproducir esta interpretación de Julio Porres Martín-Cleto: «Otro templo visigodo, llamado de la Cruz y entonces extramuros (?), es probablemente el edificio rehecho para mezquita en 999, devuelto luego al culto cristiano y hoy ermita del Cristo de la Luz». Ya González-Simancas deja dicho en 1929, amparándose en la lectura de la inscripción fundacional de Amador de los Ríos, que el templo, todo él islámico, fue reconstruido o renovado en su parte superior. Pasando a la etapa cristiana, Julio González exhibe documento de instauración en 1182 de la iglesia de Santa Cruz por el arzobispo don Gonzalo Pérez, a instancias del rey Alfonso VIII, a favor de los hospitalarios u Orden de San Juan, iniciándose así el culto católico en la mezquita, pero sin saberse qué suerte corrió el monumento entre 1085 y 1182, si estaba ya abierto al nuevo culto o permaneció cerrado, como propone Julio Porres. De otra parte, González Simancas alude al libro Becerro de la Catedral: en 1186 se hacía donación del templo a la Orden de San Juan «De institucione invocacionis ecclesie Sancte Crucis, que est iusta Valmardun».

En el Cristo de la Luz, el año 999 sería referencia cronológica del acabado de una remodelación muy radical de obra anterior cuyos testimonios arquitectóni- 
cos he intentado exponer. El sector de la ciudad en que se levanta la mezquita que estudiamos tiene probada antigüedad, por allí mismo Bāb al-Mardūm, cuyos arcos de medio punto enjarjados y sin alfiz nos podrían llevar a los principios de la dominación musulmana, o incluso a época preislámica, pues está probado que ese tipo de arcos se hacía en lo bajorromano -ruinas de Dugga y Cartago, en Túnez y en ladrillo los arcos inferiores del acueducto de los Milagros en Mérida - y quizá en lo godo, y no muy por debajo de esa entrada, parte de una alcantarilla romana con arco de medio punto de recia sillería. De otra parte, el revestimiento exterior o actualización de edificio viejo ha tenido ejemplos a lo largo de la historia; en lo islámico la Mezquita Mayor de Córdoba: la expresada Puerta de San Esteban para el siglo Ix y el añadido de la fachada para el siglo $\mathrm{X}$ del patio; citaré también el caso del alminar de la mezquita de Sfax que oculta, según L. Lucien, otro anterior del siglo IX, y lo mismo cabría decir de la torre cristiana de Santa María de Niebla explorada por Alfonso Jiménez con viejo alminar dentro posiblemente del siglo Ix. Dice el Muqtabis $V$ de Ibn Hayyān que en Córdoba por incendio quedó destruida la mezquita de Abū Hārūn (del siglo IX) siendo reconstruida por 'Abd al-Raḥmān III, «según era antes, pero con mejor construcción y fábrica perfecta». Pasando a la cristianización de la mezquita del Cristo de la Luz, tiene ésta el privilegio de ser única en la Península: templo islámico que recibió ábside mudéjar del siglo xIII, bien por la veneración del edificio a raíz de 1085, en que se consagraría al culto cristiano, o porque allí mismo hubo templo godo suplantado por mezquita, aquél con advocación de Santa Cruz, lo que como hemos visto no se ha podido probar a nivel arqueológico.

Como conclusión final, es de lógica constructiva admitir una mezquita emiral en el Cristo de la Luz, modesta, de un solo cuerpo, cubiertas abovedadas de ladrillo o cubrición de madera, erigida con muros de mampostería y esquinales de ladrillo vistos al exterior (Figura 1 A y B), con los 12 arcos del interior más los adheridos a paramentos para anular empujes; sin ningún tipo de contrafuertes exteriores. En 999 se refuerza, a la vez que se decora el templo al exterior, adosando a la vieja mampostería los pilares y arquerías, recreciéndose por tanto en altura para instalar las nuevas cúpulas nervadas de estilo califal. Si el oratorio se hubiera levantado entero en 999 , sin duda todo él enseñaría sólo ladrillo como material constructivo, máxime tratándose de edificio de escala reducida, con lo que los ladrillos de los pilares y decoración exterior trabarían perfectamente, sin el recurso improcedente del adosado, con los ladrillos de los muros exteriores.

Dando la espalda a las dos jornadas constructivas que venimos defendiendo con intervalo de tiempo desconocido, es posible que el constructor del Cristo de la Luz del año 999 recurriera a aquel recurso de obra exterior adosada, evitan- 
do al edificio complicados engarces o acoplamiento de ladrillos en la dura mampostería del fondo, es decir, dos jornadas constructivas en 999: se erige la caja de mampostería y de seguido se la envuelve con la obra decorativa de ladrillo añadiéndose las nueve cupulillas; pero todo ello en contradicción con lo que parece habitual en el Toledo medieval, empezando por el mismo Cristo de la Luz visto por el interior - arcos incrustados, no adosados, en la mamposteríay los ejemplos de la figura 5, 1, 2 y 3 . Pudieran tener esas dos jornadas yuxtapuestas de 999 probable, aunque remota, justificación en la fachada de la Mezquita de las Tres Puertas de Qayrawān, levantada por un andaluz, documentada en el siglo IX, cuya fachada exterior luce tres arcos muy sobresalientes al parecer adosados al muro de fina sillería del fondo, si bien se trata de monumento muy reformado a lo largo de su historia. Según Marçais, la antigua cubierta de este oratorio era de madera, ahora con bóvedas de medio cañón de ladrillo.

En la problemática que constituye el siglo XII toledano, que dejaron sin despejar del todo Gómez-Moreno y Torres Balbás, en mi opinión prácticamente vacío de construcciones mudéjares, se puede tomar como modelo a los efectos cronísticos y arquitectónicos el caso de San Lorenzo. Es templo citado ya en 1156 , lo que no implica que la torre-capilla del sur fuera del siglo XII, pues sus facturas constructivas y arcos delatan época muy anterior árabe; es decir, allí habría mezquita de barrio consagrada al culto cristiano en aquella centuria, con modificaciones no del todo resueltas en las últimas exploraciones del monumento que dan nuevos muros con mampostería de doble verdugada de ladrillo. Luego vino lo del templo posterior hasta nuestros días de nueva dirección E. Otros muchos templos de advocación cristiana, hoy en su mayoría con fábricas mudéjares del siglo XII-XIV, son igualmente mencionados en el XII, lo que permite generalizar en la ciudad el cliché de San Lorenzo, por otra parte bien comprobado en El Salvador, Santas Justa y Rufina y el Cristo de la Luz: San Sebastián, San Miguel, Santiago del Arrabal, San Andrés y San Bartolomé. En esta valoración no entra el problema de las celebradas seis iglesias mozárabes - San Lucas, San Sebastián, Santas Justa y Rufina, Santa Eulalia, San Torcuato y San Marcos-, porque lo que nos llega de las cinco, aún en pie, es arte mudéjar del siglo XIII y posterior; quizá con la excepción de San Sebastián, supuesto oratorio islámico, aunque radicalmente reformado en el exterior. Gómez-Moreno colocó a la cabeza de los templos mudéjares Santa Eulalia y San Lucas. El vacío de contenido mudéjar en el siglo XII es porque, como aconteció en Sevilla y Aragón en fechas posteriores, las mezquitas de barrio satisfacían al nuevo culto cristiano - también como propuso Torres Balbás probables templos mozárabes- de escasos repobladores. 
Respecto a las torres de Santiago del Arrabal, San Bartolomé y San Andrés, sus identificaciones con alminares, según propuestas en escritos míos anteriores en base a lo estructural, decorativo y estilístico, otros estudiosos del arte o la arqueología árabe y mudéjar de nuestros días los han pasado por alto quizá por respetar los criterios de Gómez-Moreno y de Torres Balbás, que casi nada escribieron de alminares en Toledo. Insostenible es la identificación de la torre tardomudéjar de San Sebastián con un viejo alminar, según propuesta de algún autor de nuestros días. González Simancas ya advirtió dos tipos de mampostería en la torre y el cuerpo del templo de Santiago del Arrabal, aventurando la hipótesis de ser aquélla alminar. Tanto las mamposterías como las ventanas a un mismo nivel de las tres torres que nos ocupan (Figuras 5-4-4-6-4) acusan mano de obra islámica de los siglos X-XI antes que mudéjar primitivo o protomudéjar. Es cierto que toda omisión de tales torres con sus evidentes arcaismos, hasta ahora apenas valorados, deja desencuadernado el proceso árabe-mudéjar toledano. Al margen de esos arcaísmos, poco trabajo costaría reconocer en Toledo lo que aconteció en ciudades hispanomusulmanas de paralelo rango artístico, Córdoba, Sevilla, Granada, y otras poblaciones inferiores, como Almonaster, Cuatrohabitan, Archez, Niebla y Ronda. En ellas se logró que permanecieran más allá de la línea de la Reconquista torres de la dominación islámica de buen arte y presencia, reciedumbre estructural y función paralela a torres campanarios. En casi todas esas torres islámicas andaluzas, como las tres toledanas, bastó con añadirles un segundo cuerpo para campanario. Esas tres torres toledanas se adscriben por la ubicación de las ventanas y trazas de sus arcos a dos tipos de alminares aún en pie: la de San Andrés con ventana en la parte superior se va con el alminar omeya de la Qarawiyyīn de Fez; y las de Santiago del Arrabal y de San Bartolomé con ventanas en medio del cuerpo emparejan con el alminar de San Juan de Córdoba y el de San José de Granada, y a más larga distancia alminares de Tị y Alcazaba de Jerez, además del alminar de la mezquita cairota de Ibn Ṭūlūn, con ventana de trazas omeyas nuestras y de aspecto muy toledano. Un tercer tipo de alminar en Toledo es el de El Salvador, completamente cerrado, sólo con algunas saeteras; el alminar de la mezquita de los Andaluces en Fez atribuido a época omeya; quizá el alminar de la mezquita de la calle Rey Heredia de Córdoba y el de Turpiana de Granada, entre otros. El cuarto tipo de alminar, el oficial forjado para mezquita metropolitana en Córdoba por obra de 'Abd al-Raḥmān III, con obligado friso en la cumbre de arquillos decorativos, está inédito en Toledo, si bien pudo haberse reflejado en el alminar de su mezquita Mayor; es muy significativo que las torres mudéjares de la ciudad, siempre de gran envergadura, de los siglos XIII y XIV exhiban en la cumbre del primer cuerpo aquel friso de arquillos. Excepto los alminares de mezquitas metropolitanas, con dos cuerpos esca- 
lonados, en Toledo y otras ciudades, debió predominar en mezquitas de barrio torre de cuerpo único con terraza - sobre la que los cristianos añadieron el cuerpo de campanas - con metrología de canon islámico, la base llevada cuatro veces a la altitud, según se ve en San Andrés y en El Salvador de Toledo. En mi criterio, en la zona toledana, la torre mudéjar más antigua es la de San Nicolás de Madrid, en la que se inauguran dos o tres registros superpuestos de arcos decorativos, probablemente de finales del siglo XII.

\section{RESUMEN}

En la inscripción árabe del exterior de la mezquita del Cristo de la Luz figura el año 999 en que se termina el templo, pero éste pudo ser anterior, remodelado o reconstruido en aquella fecha, añadiéndose el forro decorativo de ladrillos de las fachadas de la calle y del lado noroeste, además de las cúpulas califales del interior. Estudio añadido de alminares de la ciudad.

\section{ABSTRACT}

In the Arabic inscription on the exterior of the mosque «Cristo de la Luz» appears the year 999 , usually understood to signify when the building was completed. However, it might also signify remodelling or rebuilding on that date. The new features might have included the decorative brick façade on the street and nort-west side and the caliphalstyle domes in the interior. In addition, this paper includes a study of the minarets of Toledo.

\section{BIBLIOGRAFÍA}

Amador de los Ríos, R., La ermita del Santo Cristo de la Luz en Toledo. Estudio arqueológico motivado por los últimos descubrimientos de febrero de 1899. Madrid, 1899.

AmAdoR DE LOS Ríos, R., Monumentos arquitectónicos de España. Madrid, 1905.

AZUAR Ruiz, R., La rábita califal de las Dunas de Guardamar (Alicante). Alicante, 1989. BRISCH, K., Zu einer Gruppe von islamichen Kapitellen und Basen des 11 jhdts. in Toledo. Madrider Mitteilungen, 2, 1962.

CODERA, F., «Inscripción árabe de la capilla de Santa Catalina en Toledo», B.R.A.H., 1983, 434-437.

CRESwell, K. A. C., A short account of early Muslim Architecture. Baltimore, 1958. 
Creswell, K. A. C., The Muslim Architecture of Egypt, tomo I, Oxford, 1952.

Creswell, K. A. C., Early Muslim Architecture, t. II, Nueva York, 1979.

Delgado Valero, C., Toledo islámico: ciudad, arte e historia. Toledo, 1987.

EWERT, Ch., «Die Moschee am Bāb al-Mardūm in Toledo eine "Kopie" der moschee von Córdoba». Madrider Mitteilungen, 18 (1977), 287-354.

HeRnÁNDEZ GimÉnez, F., El alminar de 'Abd al-Rahmān III en la Mezquita Mayor de Córdoba. Génesis y repercusiones. Granada, 1975.

GolomBeK, L., «The abbasid Mosque at Balkh», Oriental Art, XV, 1969.

Golvin, L., Essai sur l'architecture religieuse musulmane. L'art Hispano-musulman, IIIIV. París, 1979.

GÓMEZ-MORENo, M., Arte mudéjar toledano. Madrid, 1916.

Gómez-Moreno, M., El arte árabe español hasta los almohades. Ars Hispaniae, III. Madrid, 1951, 199-212.

GonZÁlez PAlEnCIA, A., Los mozárabes de Toledo en los siglos XII y XIII, tomo IV. Madrid, 1926-1930.

GonZÁlez Simancas, M., Toledo. Sus monumentos y el arte ornamental. Madrid, 1929.

IBN HaYYān, Crónica del califa 'Abd al-Rahmān III an-Nāṣir entre los años 912 y 942. Trad., notas e índices de Viguera, M. J. y Corriente, F., Zaragoza, 1981.

IZquierdo BENITO, R., y PRIETo VÁzqueZ, G., «Una pequeña mezquita encontrada en Vascos (Navalmoralejo, Toledo)», Cuadernos de la Alhambra, 29-30 (1993-94), 21-38.

JimÉNEZ MARTín, A., La mezquita de Monaster. Huelva, 1975.

KING, G., «The Mosque Bab al-Mardum in Toledo and the influences acting upon it», Art and Archaeology Research Paper, 2 (1972), 29-40.

LÉVI-ProvenÇaL, E., Inscriptions arabes d'Espagne, I-II. París, 1931.

MarÇAIS, G., L'architecture musulmane d'Occident. Tunis, Algérie, Maroc, Espagne et Sicilie. París, 1954.

OCAÑA JIMÉNEZ, M., «La inscripción fundacional de la mezquita de Bāb al-Mardūm en Toledo», Al-Andalus, XIV (1949), 175-183.

Passini, J., Rojas RodrígueZ-Malo, J. M., Villa, J. R. «Los baños extramuros de San Sebastián», Al-Qantara, XVIII (1997), 187-219.

Pavón Maldonado, B., Memoria de la excavación de la mezquita de Madinat al-Zahra. Madrid, 1966.

Pavón Maldonado, B., Arte toledano: islámico y mudéjar. Madrid, 1988.

PAVÓn Maldonado, B., «Arte islámico y mudéjar en Toledo. Hacia unas fronteras arqueológicas», Al-Qantara, II (1981), 383-427 y III (1982), 415-45.

PAvón MALDONADO, B., «Arte islámico y mudéjar en Toledo. La supuesta mezquita de las Santas Justa y Rufina y la Puerta del Sol», Al-Qanțara, XI (1990), 509-526.

Pavón Maldonado, B., Tratado de arquitectura. Agua, I. Madrid, 1990.

Pavón Maldonado, B., «La Puerta de Bisagra Vieja de Toledo. Nuevas orientaciones sobre la arquitectura medieval toledana», Toletum, 32 (1995), 85-119.

PAVÓN MALDONADO, B., «Arte islámico en Toledo y Tudela», Revista del Instituto Egipcio de Estudios Islámicos en Madrid, XXVII (1995), 104-140.

Paz Escribano, M. DE y JuAn García, A. DE, «Iglesia de Santa Justa y Rufina, Toledo; Arqueología en la ciudad. Patrimonio Histórico-Arqueología 13, 1996, Servicio de Publicaciones de la Junta de Comunidades de Castilla-La Mancha. 
PoRres MARTín-Cleto, J., «La mezquita toledana del Solarejo llamada de Las Tornerías», Al-Qantara, IV (1983), 411-421.

PONS BoIGUES, F., Apuntes sobre las escrituras mozárabes toledanas. Madrid, 1897.

PUERTAS TRICAS, R., Iglesias hispánicas (siglos IV al VIII). Testimonios literarios. Madrid, 1975.

RivorRA, G. T., Archittetura musulmana. Milán, 1914.

Siroux, M., Anciennes voies et monuments routiers de la Región d'Ispahan suivi de plusiers autres edifices de cette province. El Cairo, 1971.

TERrasse, H., Arte hispano-mauresque des origines au XIIIe siècle. París, 1932.

TORRES BALBÁs, L., «Arte hispanomusulmán hasta la caída del Califato de Córdoba», Historia de España, V, dirigida por R. Menéndez Pidal. Madrid, 1957, 606-612.

Torres BalBás, L., «Por el Toledo mudéjar», Al-Andalus, XXIII (1958), 424-440. 